\title{
Osteoporosis and Health-Related Quality of Life among Older Women
}

\author{
Ashley Wilson ${ }^{1 *}$, Gina Maiocco ${ }^{2}$, Usha Sambamoorthi ${ }^{3}$ \\ ${ }^{1}$ West Virginia University School of Nursing, USA \\ ${ }^{2}$ University of Phoenix, USA \\ ${ }^{3}$ West Virginia University School of Pharmacy, USA \\ Corresponding author: wilsonash@hsc.wvu.edu
}

\begin{abstract}
Background: Osteoporosis, a systemic skeletal disease characterized by low bone mass, poses a significant disease burden for older women. Often assessed using Health-Related Quality of Life (HRQoL) scale, the association between osteoporosis and HRQoL is scarce, with the majority of quality of life studies focused on osteoporotic women post fracture.

Purpose: The study's primary objectives were to examine if differences exist in HRQoL among women greater than 50 years of age who have and/or do not have osteoporosis and to gain insight into the relationship of HRQoL and osteoporosis.

Methods: A retrospective cross-sectional design involving data extraction on women aged 50 years or older from 2014 Medical Expenditure Panel Survey (MEPS) was used ( $\mathrm{N}=$ 4,661). HRQoL was measured by the generic Short-Form-12 Version 2 Physical (PCS) and Mental Health (MCS) component summary scores. The differences between osteoporosis and PCS and MCS were examined using t-tests and multivariable ordinary least squares regression.

Results: Overall, 4.1\% women aged 50 and older had osteoporosis. In both bivariate and multivariable analyses, no statistically significant differences were observed in HRQoL measures between women with and/or without osteoporosis.

Conclusion: No group differences in HRQoL by osteoporosis status suggest the need for additional research using other research methodologies to flush out nuances in QOL changes. Clinician actions focused on insured and uninsured women with osteoporosis must include early and ongoing QOL assessment, with a focus on physical changes overtime.
\end{abstract}

Keywords: Osteoporosis, Quality of Life, Health-Related Quality of Life. 
Journal Of Nursing Practice

http://thejnp.org

ISSN: 2614-3488 (print); 2614-3496 (online)

Vol.4 No.1. October 2020. Page.70-83

\section{BACKGROUND}

Osteoporosis is a chronic multifactorial systemic skeletal disease characterized by low bone mass and micro-architectural deterioration of bone tissue (Nuti, Caffarelli, Giuseppe, Gennari, \& Stafano, 2014, p. 2255). This condition impacts an estimated 10. 2 million (10.3\%) adults aged 50 or older in the United States (U.S.) with the overwhelming majority $(80.3 \%)$ being women (8.2 million) (Wright et al, 2014). Current statistics reveal non-Hispanic women greater than 50 years of age have a $7 \%$ increase in probability of hip fracture in 10 years versus a $72 \%$ probability of hip fracture for those greater than 80 (Looker, Isfahani, Fan, \& Shepherd, 2017). Therefore, as the general population ages, the rate of osteoporosis will likely increase and may negatively impact a woman's physical and psychological health. Older women may suffer a decline in physical functioning due to agerelated biological changes. From 2002 to 2013, Avis et al (2018) used the physical and mental components of the SF-36 to assess midlife predictors of HRQoL in 2,614 older women. Study results showed as women aged a decline in physical components (51.6 to 47.1) occurred but the mental component slightly elevated (49.2 to 53.1). Predictors of lower physical scores included aging, higher body mass index, smoking, two or more medical conditions, sleep problems, and urinary incontinence. Although not singled out in this study as an influential medical condition to HRQoL, the role osteoporosis may play on physical and mental function warrants further appraisal.

Trepidation toward osteoporosis is due to the burden it can pose on those who develop the condition. Burden relates to quality of life (QOL) which for woman with osteoporosis can mean decreased physical function, pain, decreased social function, and decreased feelings of wellbeing. To assess this burden, the Health-Related Quality of Life (HRQoL) subjective outcome measure can be used. Results of this tool describe the perceived health status of an individual (Salaffi et al., 2007, Adachi et al., 2010) and benefits of interventions related to patient centered care (Luo et al, 2015). HRQoL is measured using generic or disease specific instruments, like the Short Form -36 (SF 36), with overall results used to provide direction in the care of adults with chronic conditions (Hand, 2016).

Before talking about QOL in women with osteoporosis, a brief mention of QOL in women at midlife (47-69) requires mentioning. From 2002 to 2013, Avis et al (2018) used the physical and mental components of the SF-36 to assess midlife predictors of HRQoL in 2,614 older women. Study results showed as women aged a decline in physical components (51.6 to 47.1) occurred but the mental component slightly elevated (49.2 to 53.1). Predictors of lower physical scores included aging, higher body mass index, smoking, two or more medical conditions, sleep problems, and urinary incontinence. Although not singled out in this study as an influential medical condition to HRQoL, the role osteoporosis may play on physical and mental function warrants further appraisal.

Quality of life in women with osteoporosis has been examined quantitatively and qualitatively. Quantitative QOL studies concentrated on adults with multiple chronic conditions or osteoporotic fractures. For instance, Salaffi et al. (2007) examined the burden of prevalent fractures on HRQoL in postmenopausal women with primary osteoporosis using the mini-Osteoporosis Quality of Life Questionnaire (mini-OQLQ), the Medical Outcomes Study SF-36, and the EuroQuol-5D (EQ-5D). The results of this cross-sectional study indicated that vertebral fractures related to osteoporosis, the number of fractures, the presence of comorbid conditions, and age were associated with lower HRQoL (Salaffi et al., 2007).

Concerning presence of co-morbidities, the Global Longitudinal Study of Osteoporosis in Women (2010) compared several dimensions of HRQoL in postmenopausal women with prior fractures with HRQOL of women who had other chronic conditions like 


\section{Journal Of Nursing Practice}

http://thejnp.org

ISSN: 2614-3488 (print); 2614-3496 (online)

Vol.4 No.1. October 2020. Page.70-83

diabetes, arthritis, and lung disease. Women in this study came from 10 countries in Europe, North America, and Australia and completed the SF-36 subscales on physical function, vitality, and self-reported general health status to determine HRQoL. This study revealed the HRQoL for women with multiple fractures or fractures of the spine, hip or upper leg were similar or worse than HRQoL scores of women with chronic conditions.

Qualitative research has looked at woman's experiences of living with osteoporosis. Based on the QOL premise that being diagnosed with osteoporosis may lead to psychological and physical consequences, women who had not experienced osteoporotic fracture found adjusting to the condition was a multifaceted process highly influenced by medical treatment and daily life (Hansen et al, 2017). How to move beyond the diagnosis of a chronic illness was a major factor for women in this study.

The work by Hansen and colleagues (2017) highlight an important void in research. The majority of woman with osteoporosis have not had a fracture but little inquiry into their quality of life has occurred. In the National Health Statistics Report for Osteoporosis (2017), $65.8 \%$ of women greater than 40 years old (1107 of 1581) did not have bone breakage prior to diagnosis. This is important detail because clinicians could be inefficiently addressing the needs of this patient population.

In lieu of research inconsistencies and the requisite to address the needs of the greater population, one must take a closer look to see if there are differences in HRQoL for women without osteoporosis versus those women with osteoporosis without fracture. Such a comparison is important so health care teams can gain a better understanding of the impact of the osteoporotic disease process on HRQoL. Results of such a study may be used by clinicians to stimulate increase frequency of QOL assessments of osteoporotic women to prevent fracture and to promote self- management of their complex condition.

\section{OBJECTIVE}

The primary objectives of this study were to examine if differences exist in HRQoL among women greater than 50 years of age who have and/or do not have osteoporosis and to gain insight into the relationship of HRQoL and osteoporosis. Using data from the Medical Expenditure Panel Survey (MEPS) on female participants aged 50 and older, we hypothesize that HRQoL will be lower in women with osteoporosis compared to women without osteoporosis.

\section{METHODS}

Study Design

The study used a retrospective cross-sectional design with survey data obtained from the 2014 Medical Expenditure Panel Survey (MEPS). MEPS is a set of large-scale household surveys that collects data from the noninstitutionalized civilian population (Agency for Healthcare Research and Quality, 2019). These annual surveys look at specific health services used and the quality of health insurance available/held by workers in the United States (Agency for Healthcare Research and Quality, 2019). For our study, we used the medical conditions file and the household consolidated file. The household consolidated file contains information on demographic and socioeconomic characteristics of participants, their health conditions, employment status, access to care, and health care satisfaction (Meraya, Raval, \& Sambamoorthi, 2015). The medical conditions file provides information on medical conditions recorded verbatim and coded using the International Classification of Diseases, $9^{\text {th }}$ Edition, Clinical Modification (ICD-9-CM). (Agency for Healthcare Research and Quality, 2019). MEPS investigators grouped these codes into conditions using the clinical classification software (CCS). 


\section{Journal Of Nursing Practice}

http://thejnp.org

ISSN: 2614-3488 (print); 2614-3496 (online)

Vol.4 No.1. October 2020. Page.70-83

\section{Study Sample}

The study sample included 4,461 participants and consisted of women with and without osteoporosis, who were aged 50 and older, who were alive during the calendar year, and who did not have any missing values in the HRQoL measures. We excluded women without health insurance coverage $(\mathrm{N}=381)$ because insurance coverage may affect HRQoL among women with and without osteoporosis.

Note: Based on 4,461 adult participants aged 50 years or older with insurance coverage, who were alive during the calendar year and did not have missing values in health-related quality life measures. Due to missing data in variables (obesity, smoking status and physical activity) the number may not add to 4,461. GERD: Gastroesophageal Reflux Disease; HS: High School; LT: Less than; Rx: Prescription Drug; Cov: Coverage; Wt.: Weighted

\section{Dependent Variable: HRQoL Measures}

In this study, HRQoL measures were derived from by the Short Form Survey-12 Version 2 (SF12-V2). The SF12-V2 is a 12-item multi-purpose survey used to evaluate HRQoL components, specifically physical and mental health functioning of individuals (Ware, Kosinski, \& Keller, 1996). It includes eight domains (role physical, role emotional, physical function, social function, mental health, vitality, pain, and general health) and is operationalized into physical component summary (PCS) and mental component summary (MCS) scores. Both PCS and MCS range from 0 to 100, with 0 representing the lowest level of health and 100 the highest. In the MEPS, HRQoL is administered as a mail-in-survey.

\section{Key Independent Variable: Osteoporosis (Yes/No)}

The presence or absence of osteoporosis was derived from the Medical Conditions file by using the CCS code 206. The CCS code of 206 represents the following ICD-9-CM codes specific to osteoporosis: 73300, 73301, 73302, 73303, and 73309. The initial capturing of osteoporosis data in MEPS included specifically asking respondents to identify (1) a physical or mental health conditions regardless of whether they sought medical care or experienced disability during the interview period; (2) if they sought care for osteoporosis either in an inpatient or outpatient setting, emergency room or during a home health visit; (3) if they reported a medical condition (example: osteoporosis) as bothersome during the interview; and (4) if they had disability days due to the condition (Machlin, 2019)

\section{Other Explanatory Variables:}

The selection of other explanatory variables that have been found to influence HRQoL was guided by the Andersen Behavioral Model (Andreson, 1995). According to this model, HRQoL can be affected by predisposing variables, enabling factors, needs factors, personal health practices, and the external environment. For this study, we identified predisposing factors as age (50-64 \& 64 and older) and race/ethnicity (white \& non-white). Enabling factors, the financial or organizational factors that enable health service utilization (Babitsch et al, 2012) included marital status (married/not married); education (less than high school, high school, and above); employment (employed/non-employed), poverty level (Poor/Near Poor, Middle Income, High Income), health insurance (private, public), and prescription coverage (yes/no). The needs factors which represent the perceived and evaluative need for health services included the following variables: asthma (yes, no), arthritis (yes, no), cancer (yes, no), diabetes (yes, no), GERD (yes, no), thyroid disease (yes, no), cardiovascular disease (yes, no), depression (yes, no), and anxiety (yes, no). Personal health practices that are linked to osteoporosis included smoking status (current smoker, 


\section{Journal Of Nursing Practice}

http://thejnp.org

ISSN: 2614-3488 (print); 2614-3496 (online)

Vol.4 No.1. October 2020. Page.70-83

other), moderate or vigorous physical activity 5 or more times/week (yes/no), and obesity (yes/no) External environment was represented by participants' region of residence (northeast, Midwest, south, west).

\section{Statistical Analysis}

Group differences in osteoporosis status were analyzed using the Rao-Scott chisquare tests. The unadjusted relationships between osteoporosis and HRQoL measures were analyzed using independent t-tests. A multivariable ordinary least square regression (OLS) was used to assess the adjusted relationships between osteoporosis and HRQoL measures. The multivariable OLS regressions not only controlled for osteoporosis, but also the predisposing, enabling, need factors, personal health practices, and external environment. All analyses accounted for the multistage clustered sampling of the MEPS with survey procedures in SAS 9.4.

\section{RESULTS}

Description of the Study Sample

The study sample consisted of 4,461 participants, with the majority being nonHispanic white women (73.4\%). Age distribution showed that $53.2 \%$ of women were aged 50 to 64 and $46.8 \%$ were aged 65 and older. Most participants had at least a high school education $(87.8 \%)$ and private insurance $(69.2 \%)$. It was also found that $9.3 \%$ had asthma, $19.3 \%$ had diabetes, and $19.7 \%$ had cardiovascular disease (Table1).

Table 1. Characteristics of the Study Sample

Older Women (age $\geq 50$ years)

Medical Expenditure Panel Survey, 2014

\begin{tabular}{|c|c|c|}
\hline \multirow[b]{2}{*}{ ALL } & $\mathbf{N}$ & \multirow[b]{2}{*}{100.0} \\
\hline & 4,461 & \\
\hline \multicolumn{3}{|l|}{ Race } \\
\hline White & 2,238 & 73.4 \\
\hline Non-White & 2,223 & 26.6 \\
\hline \multicolumn{3}{|l|}{ Age } \\
\hline 50-64 years & 2,463 & 53.2 \\
\hline 65, or Older & 1,998 & 46.8 \\
\hline \multicolumn{3}{|l|}{ Married } \\
\hline Married & 2,090 & 54.6 \\
\hline Not Married & 2,371 & 45.4 \\
\hline \multicolumn{3}{|l|}{ Education } \\
\hline LT HS & 839 & 12.2 \\
\hline HS \& above & 3,590 & 87.8 \\
\hline \multicolumn{3}{|c|}{ Employment Status } \\
\hline Employed & 1,929 & 45.2 \\
\hline Not Employed & 2,532 & 54.8 \\
\hline \multicolumn{3}{|l|}{ Poverty Status } \\
\hline Low Income & 1,701 & 28.8 \\
\hline Middle Income & 1,281 & 26.6 \\
\hline High Income & 1,479 & 44.6 \\
\hline \multicolumn{3}{|l|}{ Health Insurance } \\
\hline Private & 2,722 & 69.2 \\
\hline
\end{tabular}




\section{Journal Of Nursing Practice}

Table 1. Characteristics of the Study Sample

Older Women (age $\geq 50$ years)

Medical Expenditure Panel Survey, 2014

\begin{tabular}{|c|c|c|}
\hline \multirow[b]{2}{*}{ ALL } & $\mathbf{N}$ & Wt. \% \\
\hline & 4,461 & 100.0 \\
\hline Public & 1,739 & 30.8 \\
\hline \multicolumn{3}{|l|}{ Rx. Coverage } \\
\hline Yes & 2,211 & 56.0 \\
\hline No & 2,250 & 44.0 \\
\hline \multicolumn{3}{|l|}{ Asthma } \\
\hline Asthma & 456 & 9.3 \\
\hline No Asthma & 4,005 & 90.7 \\
\hline \multicolumn{3}{|l|}{ Arthritis } \\
\hline Arthritis & 2,174 & 47.7 \\
\hline No Arthritis & 2,287 & 52.3 \\
\hline \multicolumn{3}{|l|}{ Cancer } \\
\hline Cancer & 536 & 14.3 \\
\hline No Cancer & 3,925 & 85.7 \\
\hline \multicolumn{3}{|l|}{ Diabetes } \\
\hline Diabetes & 1,029 & 19.3 \\
\hline No Diabetes & 3,432 & 80.7 \\
\hline \multicolumn{3}{|l|}{ (Continued) } \\
\hline \multicolumn{3}{|l|}{ GERD } \\
\hline GERD & 673 & 15.4 \\
\hline No GERD & 3,788 & 84.6 \\
\hline \multicolumn{3}{|l|}{ Thyroid } \\
\hline Thyroid & 729 & 18.7 \\
\hline No Thyroid & 3,732 & 81.3 \\
\hline \multicolumn{3}{|l|}{ Heart Disease } \\
\hline Yes & 884 & 19.7 \\
\hline No & 3,577 & 80.3 \\
\hline \multicolumn{3}{|l|}{ Depression } \\
\hline Depression & 817 & 19.2 \\
\hline No Depression & 3,644 & 80.8 \\
\hline \multicolumn{3}{|l|}{ Anxiety } \\
\hline Anxiety & 661 & 16.5 \\
\hline No Anxiety & 3,800 & 83.5 \\
\hline \multicolumn{3}{|l|}{ Obesity } \\
\hline Obese & 1,612 & 33.0 \\
\hline Not Obese & 2,777 & 65.2 \\
\hline \multicolumn{3}{|l|}{ Smoking } \\
\hline Current Smoker & 518 & 11.1 \\
\hline Other & 3,852 & 87.1 \\
\hline \multicolumn{3}{|l|}{ Exercise } \\
\hline 5 times/week & 1,848 & 43.7 \\
\hline Other & 2,590 & 55.9 \\
\hline
\end{tabular}




\section{Journal Of Nursing Practice}

http://thejnp.org

ISSN: 2614-3488 (print); 2614-3496 (online)

Vol.4 No.1. October 2020. Page.70-83

Table 1. Characteristics of the Study Sample

Older Women (age $\geq 50$ years)

Medical Expenditure Panel Survey, 2014

\begin{tabular}{lrrr}
\hline ALL & N & Wt. \% & \\
\hline Region & $\mathbf{4 , 4 6 1}$ & $\mathbf{1 0 0 . 0}$ \\
Northeast & & & \\
Midwest & 780 & 19.2 \\
South & 833 & 22.2 \\
West & 1,698 & 36.9 \\
& 1,150 & 21.8
\end{tabular}

Note: Based on 4,461 adult participants aged 50 years or older with insurance coverage, who were alive during the calendar year and did not have missing values in health-related quality life measures. Due to missing data in variables (obesity, smoking status and physical activity) the number may not add to 4,461. GERD: Gastroesophageal Reflux Disease; HS: High School; LT: Less than; Rx: Prescription Drug; Cov: Coverage; Wt.: Weighted

Description of the Study Sample by Osteoporosis

Overall $4.1 \%$ of participants had osteoporosis (Table 2). Significant group differences in osteoporosis were observed by race, age, employment, type of health insurance, prescription drug coverage, co-occurring conditions (cardiovascular disease, GERD, obesity, etc), nicotine use, amount of physical activity per week, report of pain and region. For example, a higher percentage of women aged 65 years or older reported osteoporosis compared to women in the age group 50-64 (6.7\% versus $1.8 \%$; $p<0.001)$. An increased rate of osteoporosis was reported in unemployed women without prescription coverage when compared to employed women $(5.6 \%$ versus $2.3 \%$; $<<0.001)$ with prescription coverage $(5.7 \%$ versus $2.9 \%$; $<<0.001)$.

Table 2. Characteristics of the Study Sample by Osteoporosis Status

Older Women (age $\geq 50$ years)

Medical Expenditure Panel Survey, 2014

\begin{tabular}{|c|c|c|c|c|c|c|}
\hline \multirow[b]{3}{*}{ ALL } & \multicolumn{2}{|c|}{ Osteoporosis } & \multicolumn{2}{|c|}{ No Osteoporosis } & \multirow[t]{3}{*}{ Chisq-val } & \multirow[t]{3}{*}{ P-value } \\
\hline & $\mathbf{N}$ & Wt. \% & $\mathbf{N}$ & Wt. \% & & \\
\hline & 168 & 4.1 & 4,293 & 95.9 & & \\
\hline \multicolumn{7}{|l|}{ Race } \\
\hline White & 84 & 4.1 & 2,154 & 95.9 & 0.009 & 0.923 \\
\hline Non-White & 84 & 4.1 & 2,139 & 95.9 & & \\
\hline \multicolumn{7}{|l|}{ Age } \\
\hline 50-64 years & 44 & 1.8 & 2,419 & 98.2 & 45.200 & $<0.001$ \\
\hline 65, or Older & 124 & 6.7 & 1,874 & 93.3 & & \\
\hline \multicolumn{7}{|l|}{ Married } \\
\hline Married & 78 & 4.0 & 2,012 & 96.0 & 0.031 & 0.861 \\
\hline Not Married & 90 & 4.2 & 2,281 & 95.8 & & \\
\hline \multicolumn{7}{|l|}{ Education } \\
\hline LT HS & 40 & 5.5 & 799 & 94.5 & 2.053 & 0.152 \\
\hline HS \& above & 127 & 3.9 & 3,463 & 96.1 & & \\
\hline
\end{tabular}




\section{Journal Of Nursing Practice}

http://thejnp.org

ISSN: 2614-3488 (print); 2614-3496 (online)

Vol.4 No.1. October 2020. Page.70-83

Table 2. Characteristics of the Study Sample by Osteoporosis Status

Older Women (age $\geq 50$ years)

Medical Expenditure Panel Survey, 2014

\begin{tabular}{|c|c|c|c|c|c|c|}
\hline \multirow[b]{3}{*}{ ALL } & \multicolumn{2}{|c|}{ Osteoporosis } & \multicolumn{2}{|c|}{ No Osteoporosis } & \multirow[t]{3}{*}{ Chisq-val } & \multirow[t]{3}{*}{ P-value } \\
\hline & \multirow[t]{2}{*}{$\mathbf{N}$} & Wt. \% & \multirow[b]{2}{*}{4,293} & Wt. \% & & \\
\hline & & 4.1 & & 95.9 & & \\
\hline Employed & 41 & 2.3 & 1,888 & 97.7 & 18.096 & $<0.001$ \\
\hline Not Employed & 127 & 5.6 & 2,405 & 94.4 & & \\
\hline \multicolumn{7}{|l|}{ Poverty Status } \\
\hline Low Income & 77 & 5.0 & 1,624 & 95.0 & 3.483 & 0.175 \\
\hline Middle Income & 48 & 4.6 & 1,233 & 95.4 & & \\
\hline High Income & 43 & 3.2 & 1,436 & 96.8 & & \\
\hline \multicolumn{7}{|l|}{ Health Insurance } \\
\hline Private & 81 & 3.3 & 2,641 & 96.7 & 9.133 & 0.003 \\
\hline Public & 87 & 6.0 & 1,652 & 94.0 & & \\
\hline \multicolumn{7}{|l|}{ Rx. Coverage } \\
\hline Yes & 56 & 2.9 & 2,155 & 97.1 & 11.756 & $<0.001$ \\
\hline No & 112 & 5.7 & 2,138 & 94.3 & & \\
\hline \multicolumn{7}{|l|}{ Asthma } \\
\hline Asthma & 19 & 3.1 & 437 & 96.9 & 0.988 & 0.320 \\
\hline No Asthma & 149 & 4.2 & 3,856 & 95.8 & & \\
\hline \multicolumn{7}{|l|}{ Arthritis } \\
\hline Arthritis & 90 & 4.4 & 2,084 & 95.6 & 0.417 & 0.518 \\
\hline No Arthritis & 78 & 3.9 & 2,209 & 96.1 & & \\
\hline \multicolumn{7}{|l|}{ Cancer } \\
\hline Cancer & 22 & 5.5 & 514 & 94.5 & 1.376 & 0.241 \\
\hline No Cancer & 146 & 3.9 & 3,779 & 96.1 & & \\
\hline \multicolumn{7}{|l|}{ Diabetes } \\
\hline Diabetes & 39 & 4.8 & 990 & 95.2 & 0.658 & 0.417 \\
\hline $\begin{array}{l}\text { No Diabetes } \\
\text { (Continued) }\end{array}$ & 129 & 4.0 & 3,303 & 96.0 & & \\
\hline \multicolumn{7}{|l|}{ GERD } \\
\hline GERD & 42 & 5.8 & 631 & 94.2 & 4.440 & 0.035 \\
\hline No GERD & 126 & 3.8 & 3,662 & 96.2 & & \\
\hline \multicolumn{7}{|l|}{ Thyroid } \\
\hline Thyroid & 35 & 4.5 & 694 & 95.5 & 0.306 & 0.580 \\
\hline No Thyroid & 133 & 4.0 & 3,599 & 96.0 & & \\
\hline \multicolumn{7}{|l|}{ Heart Disease } \\
\hline Yes & 39 & 5.8 & 845 & 94.2 & 3.884 & 0.049 \\
\hline No & 129 & 3.7 & 3,448 & 96.3 & & \\
\hline \multicolumn{7}{|l|}{ Depression } \\
\hline Depression & 39 & 5.4 & 778 & 94.6 & 2.509 & 0.113 \\
\hline No Depression & 129 & 3.8 & 3,515 & 96.2 & & \\
\hline \multicolumn{7}{|l|}{ Anxiety } \\
\hline Anxiety & 28 & 5.1 & 633 & 94.9 & 1.003 & 0.317 \\
\hline No Anxiety & 140 & 3.9 & 3,660 & 96.1 & & \\
\hline
\end{tabular}




\section{Journal Of Nursing Practice}

http://thejnp.org

ISSN: 2614-3488 (print); 2614-3496 (online)

Vol.4 No.1. October 2020. Page.70-83

Table 2. Characteristics of the Study Sample by Osteoporosis Status

Older Women (age $\geq 50$ years)

Medical Expenditure Panel Survey, 2014

\begin{tabular}{|c|c|c|c|c|c|c|}
\hline \multirow[b]{3}{*}{ ALL } & \multicolumn{2}{|c|}{ Osteoporosis } & \multicolumn{2}{|c|}{ No Osteoporosis } & \multirow[t]{3}{*}{ Chisq-val } & \multirow[t]{3}{*}{ P-value } \\
\hline & & Wt. \% & \multirow[b]{2}{*}{4,293} & Wt. \% & & \\
\hline & $\mathbf{N}$ & 4.1 & & 95.9 & & \\
\hline \multicolumn{7}{|l|}{ Obesity } \\
\hline Obese & 33 & 2.4 & 1,579 & 97.6 & 10.310 & 0.001 \\
\hline Not Obese & 134 & 5.1 & 2,643 & 94.9 & & \\
\hline \multicolumn{7}{|l|}{ Smoking } \\
\hline Current Smoker & 15 & 3.4 & 503 & 96.6 & 4.025 & 0.134 \\
\hline Other & 146 & 4.1 & 3,706 & 95.9 & & \\
\hline \multicolumn{7}{|l|}{ Exercise } \\
\hline 5 times/week & 72 & 3.9 & 1,776 & 96.1 & 0.245 & 0.621 \\
\hline Other & 96 & 4.3 & 2,494 & 95.7 & & \\
\hline \multicolumn{7}{|l|}{ Region } \\
\hline Northeast & 34 & 3.9 & 746 & 96.1 & 0.589 & 0.899 \\
\hline Midwest & 32 & 4.7 & 801 & 95.3 & & \\
\hline South & 55 & 4.0 & 1,643 & 96.0 & & \\
\hline West & 47 & 3.9 & 1,103 & 96.1 & & \\
\hline
\end{tabular}

Note: Based on 4,461 women aged 50 years or older with insurance coverage, who were alive during the calendar year and did not have missing values in health-related quality of life measures. Due to missing data in variables (obesity, smoking status and physical activity) the number may not add to 4,461. Significant group differences by osteoporosis were tested with Rao-Scott chi-square statistics. GERD: Gastroesophageal Reflux Disease; HS: High School; LT: Less than; Rx: Prescription Drug; Cov: Coverage; Wt.: Weighted

Unadjusted and Adjusted Associations between Osteoporosis and HRQoL Measures

Table 3 displays the parameter estimates, standard errors and 95\% confidence intervals of HRQoL scores by osteoporosis status. Even after controlling for pre-disposing variables, enabling factors, needs factors, personal health practices, and external environment characteristics, we did not observe statistically significant associations between osteoporosis and HRQoL measures. Women with osteoporosis had slightly lower MCS and PCS scores but they were not statistically significant when compared to women without osteoporosis.

Table 3. Weighted Averages and Standard Errors (SE)

Parameter Estimates from Multivariable Ordinary Least Squares Regressions on Health-Related Quality of Life Measures

Older Women (Age $\geq 50$ Years)

Medical Expenditure Panel Survey, 2014

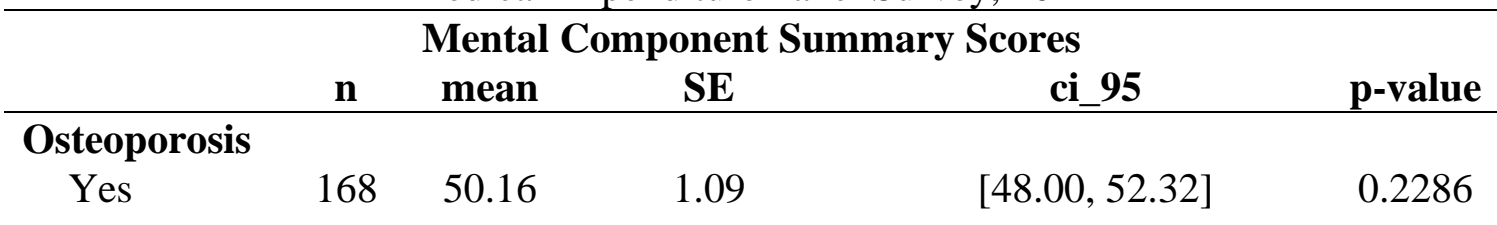


Journal Of Nursing Practice

http://thejnp.org

ISSN: 2614-3488 (print); 2614-3496 (online)

Vol.4 No.1. October 2020. Page.70-83

\begin{tabular}{|c|c|c|c|c|c|}
\hline No & 4293 & 51.50 & 0.19 & {$[51.14,51.87]$} & \multirow[b]{4}{*}{0.1074} \\
\hline \multicolumn{6}{|c|}{ Physical Component Summary Scores } \\
\hline \multicolumn{5}{|c|}{ Osteoporosis } & \\
\hline Yes & 168 & 43.02 & 1.18 & {$[40.69,45.35]$} & \\
\hline No & 4293 & 44.97 & 0.23 & {$[44.51,45.42]$} & \\
\hline \multicolumn{6}{|c|}{$\begin{array}{l}\text { Parameter Estimates from Multivariable Ordinary Least Squares Regressions } \\
\text { Mental Component Summary Scores }\end{array}$} \\
\hline & beta & SE & p-value & & \\
\hline \multicolumn{6}{|c|}{ Osteoporosis } \\
\hline Yes & -1.017 & 0.917 & 0.2689 & & \\
\hline \multicolumn{6}{|l|}{ No } \\
\hline Intercept & 54.386 & 0.675 & $<0.001$ & & \\
\hline \multicolumn{6}{|c|}{ Physical Component Summary Scores } \\
\hline \multicolumn{6}{|c|}{ Osteoporosis } \\
\hline Yes & -0.039 & 0.947 & 0.9672 & & \\
\hline No & & & & & \\
\hline Intercept & 59.200 & 0.674 & $<0.001$ & & \\
\hline
\end{tabular}

Note: Based on 4,461 adult participants aged 50 years or older with insurance coverage, who were alive during the calendar year and did not have missing values in health-related quality of life measures. The adjusted ordinary least squares regressions adjusted for age, race, marital status, education, poverty, health insurance coverage, prescription drug coverage, number of chronic conditions, depression, anxiety, obesity, smoking, and physical activity.

\section{DISCUSSION}

In this study, we looked to see if there were differences in HRQoL between women with osteoporosis and those without osteoporosis. We found no statistical significance in HRQoL measures between the groups. These results can be interpreted two ways. First, this study may truly represent what is occurring in this population. As a reminder, Avis and colleagues (2018) found women aged 47-69 without osteoporosis had declines in physical but not mental health HRQoL factors. Likewise, Hopman and colleagues (2019), showed women with Dexa-confirmed osteoporosis without fracture had large declines in HRQoL scores over a 10-year period primarily in the physical oriented domains of the SF-36. The mental domains displayed no significant differences. Therefore, our study and these two previous studies, show the groups as similar with the key QOL change involving physical function.

On the other hand, not all QOL studies on women with osteoporosis have the same results. In a study comparing QOL of women with varied bone mineral density (BMD) without fracture, QOL for osteopenic and osteoporotic women were lower than women with normal BMD in regards to pain, social function, health perception, and mental function (Baczyk, Samborski, \& Jaracz, 2016). Our study findings may be different because only $4.1 \%$ of women within our sample size of 4461 reported osteoporosis. This occurrence is lower than previously published estimates. Additionally, the difference in rates could be due to the identification method employed by the MEPS or differences in study population. As 


\section{Journal Of Nursing Practice}

http://thejnp.org

ISSN: 2614-3488 (print); 2614-3496 (online)

Vol.4 No.1. October 2020. Page.70-83

a reminder, the MEPS interviews only captures treated prevalence and not the overall prevalence of a medical condition. Therefore, those with asymptomatic osteoporosis who have not sought treatment may not have been included in the original data. Lastly, the use of the MEPS database may have also led to a lower rate of women with osteoporosis due to the exclusion of women who may be in nursing homes.

One element that did stand out in our study was the increased rate of osteoporosis reported by unemployed women without insurance coverage versus those employed and insured. It has been largely documented in the literature that insurance disparities can impact health outcomes, especially for those at risk for osteoporotic fracture (DeShields et al, 2017). Reasons for this increased prevalence can be attributed to increased prevalence of Vitamin D deficiency among the uninsured (Kakarala et al, 2007) and lack of continuity of care (Farley \& Blalock, 2009). Future research into efficacy of community outreach to uninsured women with osteoporosis without fracture can provide insight into a potentially growing situation.

Overall, because of continued inconsistencies in research on HRQoL and women with osteoporosis without fracture, clinicians may need to do the following. First, health care personnel working with older women need to be more engaged in research. Quantitative studies like ours may miss nuances women are experiencing as the disease progresses. Closed answer questions leave little room for elaboration. Increased use of qualitative methodologies to identify early clues in changes to QOL in aging women may be crucial to the eventual delivery of relevant interventions. Also, use of repetitive QOL assessments as women age, especially with a focus on physical changes, may be the key to preventing unnecessary fracture. Lastly, outreach to the noninsured population by health professionals is warranted to make sure all persons with osteoporosis receive proper treatment.

\section{Strengths and limitations}

Strengths of our study include sample size, use of reliable/valid measures to assess HRQoL, and application of a theoretical framework to guide selection of explanatory variables. All data was obtained from a nationally representative sample of civilian, noninstitutionalized household members. The SF12-v2 is a validated and widely used generic instrument to measure HRQoL. A comprehensive list of variables applicable to the osteoporotic disease process were used in adjusted models.

Limitations of our study include the following. First, this is an observational study. Use of a cross sectional approach allows for measurement of outcomes. This type of design offers a one-time measurement making causal relationships difficult to derive and makes interpretation of associations, the direction of associations and disease trends problematic. (Setia, Maninder Singh. "Methodology Series Module 3: Cross-sectional Studies." Indian journal of dermatology vol. 61, 3 (2016): 261-4. doi:10.4103/0019-5154.182410). Additionally, only a small percentage of women (4.1\%) in our study reported a diagnosis of osteoporosis which could account for why no group differences in HRQoL were seen. Finally, the absence of a longitudinal study design prohibited us from observing a potential decline in HRQoL over time.

\section{CONCLUSION}

Inconsistencies persist concerning understanding the QOL of women with osteoporosis without fracture. Many women may be unaware of the changes they are experiencing are related to osteoporosis and not just the physical effects of aging. The quantitative measures used to assess HRQoL may not be sensitive enough to pick up on the subtle changes. On the other hand, when identified, the rate of uninsured women with 


\section{Journal Of Nursing Practice}

http://thejnp.org

ISSN: 2614-3488 (print); 2614-3496 (online)

Vol.4 No.1. October 2020. Page.70-83

osteoporosis were higher bring to light the issue of consistent medical follow-up. Clinician focus should be on both the insured and uninsured. Preventative programs, early recognition, and treatment to help decrease the likelihood of fracture is the priority. Further research to identify early subtle changes to QOL before fracture is stressed.

\section{ACKNOWLEDGMENTS:}

Research reported in this paper was supported by the NIGMS of the National Institutes of Health under award number U54GM104942. The content is solely the responsibility of the authors and does not necessarily represent the official views of the National Institutes of Health.

\section{CONFLICTS OF INTEREST}

The authors have no conflicts of interest to report. 


\section{Journal Of Nursing Practice}

http://thejnp.org

ISSN: 2614-3488 (print); 2614-3496 (online)

Vol.4 No.1. October 2020. Page.70-83

\section{REFERENCES}

Adachi, J., Adami, S., GehlBach, S., et al. (2010). Impact of prevalent fractures on quality of life: Baseline results from the global longitudinal study of osteoporosis in women. Mayo Clin Proc, 85, 806-813. http://dx.doi.org/10.4065/mcp.2010.0082

Agency for Healthcare Research and Quality (2019). Medical Expenditure Panel Survey. Retrieved from: http://meps.ahrq.gov/mepsweb/about_meps/survey back.jsp

Andersen, R. (1995). Revisiting the behavior model and access to medical care: Does it matter. Journal of Health and Social Behavior, 36 (1), 1-10 http://dx.doi.org/10.2307/2137284

Avis, N., Colvin, A., Bromberger, J., \& Hess, R. (2018). Midlife predictors of Health-related Quality of Life in older women. J Gerontol A Biol Sci med Sci, 73 (11), 1574-1580. https://doi.org/10.1093/gerona/gly062

Baczyk, G., Samborski, W., \& Jaracz, K. (2016). Evaluation of the quality of life of postmenopausal osteoporotic and osteopenic women with or without fractures. Arch Med Sci, 12 (4), 819-827. http://dx.doi.org/10.5114/aoms.2015.55012

Babitsch, B., Gohl, D., \& von Lengerke, T. (2012). Re-revisiting Andersen's behavior model of health services use: A systematic review of studies from 1998-2011. GMS PsychoSocial-Medicine, 9 (Doc11), 1-15. http://dx.doi.org/10.32051/psm000089

Deshields, S., Romero, C., \& Cunningham, T. (2017). Exploring racial, gender and insurance disparities in patients with osteoporotic fractures. J Community Health, 42, 11111117. http://dx.doi.org/10.1007/s10900-017-0359-y

Farley, J., \& Blalock, S. (2009). Trends and determinants of prescription medication use for treatment of osteoporosis. Am J Health-Syst Pharm, 66, 1191-1201. http://dx.doi.org/10.2146/ajhp080248

Hopman, W., Berger, C., Joseph, L., et al. (2019). Longitudinal assessment of health-related quality of life in osteoporosis: Data from the population-based Canadian Multicentre Osteoporosis Study. Osteoporosis International, 30, 1635-1644. http://dx.doi.org/10.1007/s00198-019-05000-y

Hand, C. (2016). Measuring health-related quality of life in adults with chronic conditions in preimary care settings. Can Fam Physician, 62, e375-83. Retrieved from https://www.ncbi.nlm.nih.gov/pmc/articles/PMC4955103/

Hansen, C., Abrahamsen, B., Konradsen, H., \& Pedersen, B. (2017). Women's lived experiences of learning to live with osteoporosis: A longitudinal qualitative study. BMC Women's Health, 17, 1-12. http://dx.doi.org/10.1186/s12905-017-0377-z

Kakarala, R., Chandana, S., Harris, S., Kocharia, L., \& Dvorin, E. (2007). Prevalence of vitamin D deficiency in uninsured women. Society of General Internal Medicine, 22, 1180-1183. http://dx.doi.org/10.1007/s11606-007-0245-x

Looker, A., Isfahani, N., Fan, B., \& Shepherd, J. (2016). Trends in osteoporosis and low bone mass in older US adults, 2005-2006 through 2013-2014. Osteoporosis Int, 28, 1979-1988. http://dx.doi.org/10.1007/s00198-017-3996-1

Machlin, S., Soni, A., \& Fang Zhengyi. (2019). Understanding and Analyzing MEPS Household Component Medical Condition Data. Medical Expenditure Panel Survey. Retrieved from https://meps.ahrq.gov/survey_comp/MEPS_condition_data.shtml

Meraya, A., Raval, A., \& Sambamoorthia, U. (2015). Chronic condition combinations and health care expenditures and out-of-pocket spending burden among adults, Medical Expenditure Panel Survey, 2009 and 2011. Prev Chronic Dis, 12 (e2), 1-13. http://dx.doi.org/10.58881pcd12.140388

National Osteoporosis Association. (2017). What women need to know. Retried from: http://www.nof.org/preventing-fractures/general-facts/what-women-need-to-know/ 


\section{Journal Of Nursing Practice}

http://thejnp.org

ISSN: 2614-3488 (print); 2614-3496 (online)

Vol.4 No.1. October 2020. Page.70-83

Nuti, R., Caffarelli, C., Guglielmi, G., \& Gonnelli, S. (2014). Undiagnosed vertebral fractures influence quality of life in postmenopausal women with reduced ultrasound parameters. Clin Orthop Relat Res, 472, 2254-2261. http://dx.doi.org/10.1007/s11999-014-3588-8

Salaffi, F., Cimmino, M., Malavolta, N., et al. (2007). The burden of prevalent fractures on health-related quality of life in postmenopausal women with osteoporosis: The IMOF study. The J Rheum, 34 (7), 1551-1560. Retrieved from https://www.jrheum.org/content/34/7/1551

Setia, S. (2016). Methodology Series Module 3: Cross-sectional Studies. Indian Journal of Dermatology, 61 (3), 261-4. http://dx.doi.org/10.4103/0019-5154.182410

Ware, J., Kosinski, M., \& Keller, S. (1996). A 12-item Short-Form Health Survey: Construction of scales and preliminary tests of reliability and validity. Medical Care, 34, 220-233. http://dx.doi.org/10.1097/00005650-199603000-00003

Wright, N., Looker, A., Saag, K., Curtis, J., Deizell, E., Randall, S., \& Dawnson-Hughes, B. (2014). The recent prevalence of osteoporosis and low bone mass in the United States based on bone mineral density at the femoral neck or lumbar spine. J Bone Miner Res, 29 (11), 2520-2526. http://dx.doi.org/10.1002/jbmr.2269 